\title{
Effect of Post-Annealing Treatment on the Morphological and Optical Properties of ZnO Thin Film Fabricated by Spraying Deposition Method
}

\author{
T Darsono ${ }^{1 *}$, Muqoyyanah ${ }^{2}$, Sulhadi ${ }^{1,3}$, S Wahyuni $^{1}$, P Marwoto $^{1,3}$, and \\ Sugianto ${ }^{1,3}$ \\ ${ }^{1}$ Department of Physics, Faculty of Mathematics and Natural Science, \\ Universitas Negeri Semarang, Indonesia \\ ${ }^{2}$ Nanotechnology Research Centre, Department of Physics, Faculty of Science and Mathematics, \\ Universiti Pendidikan Sultan Idris, Malaysia \\ ${ }^{3}$ Materials Research Group, Thin Film Laboratory, Faculty of Mathematics and Natural Science, \\ Universitas Negeri Semarang, Indonesia \\ *Email: teguhfisikaunnes@mail.unnes.ac.id
}

ABSTRACT

This work investigated the effect of post-annealing treatment on the fabrication of zinc oxide $(\mathrm{ZnO})$ thin film by spraying deposition method. Based on SEM analysis, the annealed $\mathrm{ZnO}$ thin film at $400^{\circ} \mathrm{C}$ presented better uniformity as compared to the non-annealed film. Further measurement by UV-Vis revealed that the lowest optical band gap energy $\left(E_{g}\right)(3.22 \mathrm{eV})$ was achieved by $400^{\circ} \mathrm{C}$ sample. These results confirmed that post-annealing treatment enhanced the optical and morphological properties of the fabricated $\mathrm{ZnO}$ thin film.

Keywords: $\mathrm{ZnO}$; thin film; spraying; band gap energy.

\section{INTRODUCTION}

Zinc oxide $(\mathrm{ZnO})$, a wide band gap $\left(E_{g}\right)$ semiconductor material has attracted a lot of interest due to its several advantages for various optoelectronic application, such as transparent conductive oxide (TCO). An ideal TCO should possessed high optical properties, i.e. high transmittance over the visible light and low $E_{g}$ value ${ }^{[1]}$. In order to fabricate the desired $\mathrm{ZnO}$ thin films, several effort have been done including its fabrication method. Sol-gel ${ }^{[2,3]}$, chemical vapour deposition, sputtering ${ }^{[4,5]}$, laser ablation, spin or dip coating ${ }^{[2,6]}$, and spraying deposition ${ }^{[7-10]}$ were commonly used to fabricate $\mathrm{ZnO}$ thin film. Among them, spraying deposition offered a simpler fabrication method, inexpensive equipment, controllable films thickness, and suitable for large area deposition ${ }^{[7,11]}$. Commonly, high substrate temperature was needed during spraying process to evaporate the solvent. Cho et al. (2019) using $400^{\circ} \mathrm{C}$ substrate temperature and the spraying process was done for $15 \mathrm{mins}^{[8]}$. Meanwhile, higher substrate temperature of 400,450 , and $500^{\circ} \mathrm{C}$ were performed by Suárez et al. (2020) to fabricate $\mathrm{ZnO}: \mathrm{Mn}$ thin film. They found that higher substrate temperature resulted thicker film and the changes in particle's size and shape ${ }^{[9]}$. High substrate temperature also resulted a cracked to porous structure ${ }^{[12]}$.

In order to further improve the film's properties, post-annealing treatment has commonly carried out by varying its time duration or temperature. Nadarajah et al. (2013) annealed the sprayed $\mathrm{ZnO}$ thin film from 300 to $500^{\circ} \mathrm{C}$ for $2 \mathrm{~h}$. The results showed that annealing treatment affected the particle's grain size, film's thickness, and film's resistivity ${ }^{[13]}$. Lower electrical resistivity ( 8.22 to $1.12 \Omega \mathrm{cm})$ and $E_{g}$ value $(\sim 3.275$ from $3.289 \mathrm{eV})$ of the fabricated $\mathrm{ZnO}$ thin film were also observed by using annealing temperature of 450 and $500^{\circ} \mathrm{C}$ for 30 mins $^{[14]}$. Therefore, in this study, $\mathrm{ZnO}$ thin film was fabricated via spraying 
deposition method with lower substrate temperature and annealed with various temperature.

\section{METHODS}

$\mathrm{ZnO}$ thin film was fabricated by spraying deposition method as described in the previous study. In brief, zinc acetate dihydrate was dissolved into methanol under constant stirring at room temperature for $1 \mathrm{~h}$. The prepared $0.1 \mathrm{M} \mathrm{ZnO}$ solution was then sprayed to the preheated clean glass substrate $\left(250^{\circ} \mathrm{C}\right)$ with the spraying distance of $20 \mathrm{~cm}$. The sprayed film was then annealed for $1 \mathrm{~h}$ by different temperature $\left(300,350,400,450\right.$, and $\left.500^{\circ} \mathrm{C}\right)$ and further used for characterization.

\section{RESULTS AND DISCUSSION}

The morphological properties of the fabricated $\mathrm{ZnO}$ thin film annealed at $400^{\circ} \mathrm{C}$ is presented in Figure 1 (a) and (b). Based on Figure 1 (a), it was clearly seen that the film's surface presented many holes. Meanwhile, the non-annealed $\mathrm{ZnO}$ thin film presented rough surface with river-like surface (Figure 1 (c)). This was believed caused by different solvent evaporation process during the deposition process and the absence of postannealing treatment. Further cross section observation revealed the flat and smooth surface all over the substrate as the effect of post-annealing treatment (Figure 1 (b)). The uniformity of annealed film's thickness was observed in the range of $\sim 5 \mu \mathrm{m}$. In contrast, rough surface was observed for the non-annealed $\mathrm{ZnO}$ thin film with the thickness ranged from 6.87 to $30.4 \mu \mathrm{m}$ (Figure 1 (d)). Smoother surface morphology of annealed film was in a good agreement with others report ${ }^{[14-16]}$.
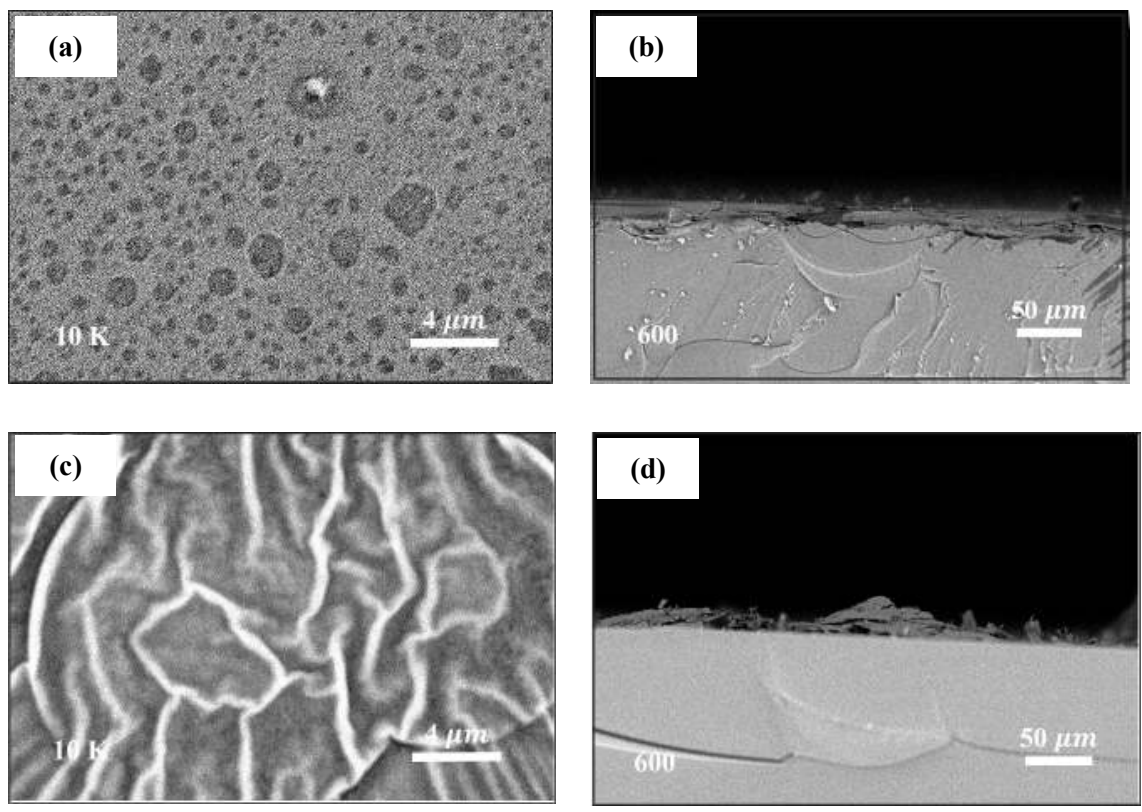

Figure 1. Top and cross section's SEM images of the fabricated $\mathrm{ZnO}$ thin film; (a)-(b) annealed at $400^{\circ} \mathrm{C}$ and (c) $-(d)$ non-annealed

Next, the optical band gap energy $\left(E_{g}\right)$ is determined based on absorption spectrum fitting (ASF) method by plotting $(\operatorname{Abs}(\lambda) / \lambda)^{2}$ vs $1 / \lambda$ data as shown in Figure $2^{[17]}$. The $\lambda_{\mathrm{g}}$ value was obtained from its linear extrapolation and further used to calculate $E_{g}$ value by using the following equation; 


$$
E_{g}=1239.83 / \lambda_{g}
$$

Based on the calculation, lower $E_{g}$ value $(3.23-3.27 \mathrm{eV})$ was obtained compared to the non-annealed film $(3.95 \mathrm{eV})$ obtained in the preliminary work. This was believed due to the decrement of amorphous phase and the improvement of film's crystallinity after postannealing treatment ${ }^{[15]}$. Among the annealed films, $\mathrm{ZnO}$ thin film annealed at $400^{\circ} \mathrm{C}$ presented the lowest $E_{g}$ value of $3.23 \mathrm{eV}$ which indicated better electron mobility ${ }^{[18]}$. This might be caused by the excess charge carriers which were activated during annealing treatment ${ }^{[13]}$. This result was in a good agreement with Periasamy et al (2010) who found that $400^{\circ} \mathrm{C}$ resulted the lowest $E_{g}$ value $(3.05 \mathrm{eV})$ compared to higher temperature $(3.26 \mathrm{eV}$ for $\left.600^{\circ} \mathrm{C}\right)^{[19]}$. Further higher post-annealing treatment $\left(450\right.$ and $\left.500^{\circ} \mathrm{C}\right)$ increased the $E_{g}$ value of 3.27 and $3.26 \mathrm{eV}$.

(a)
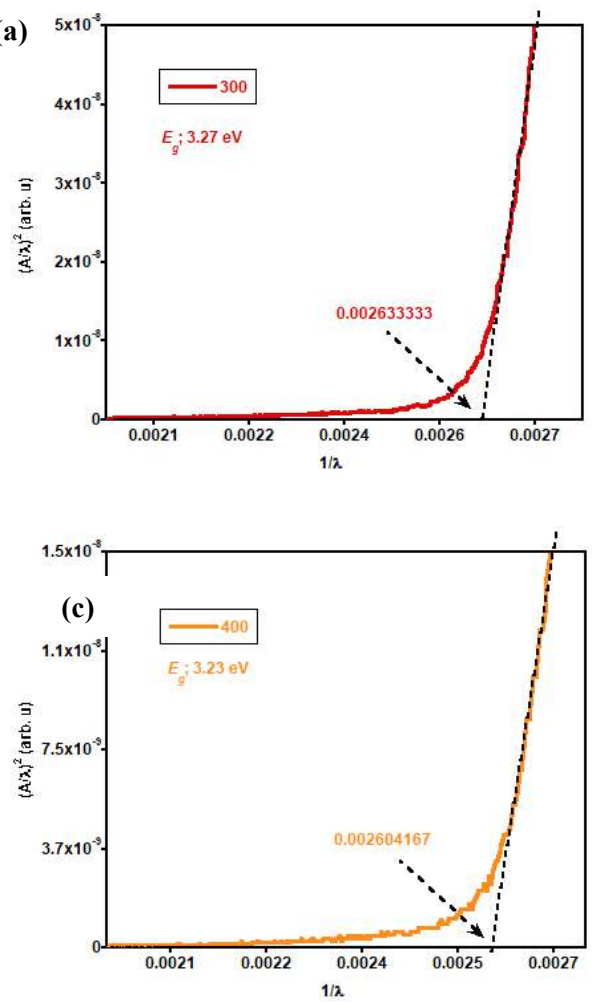

(b)

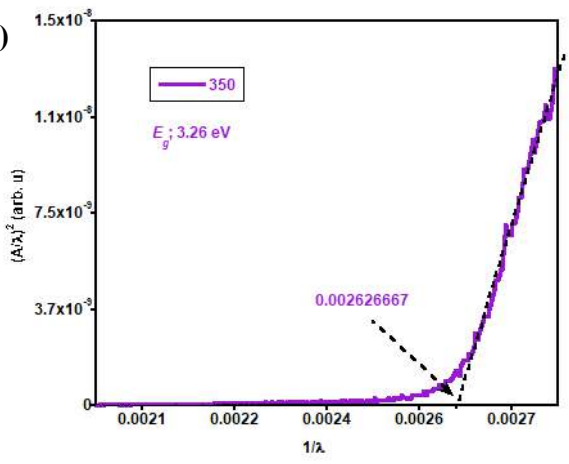

(d)

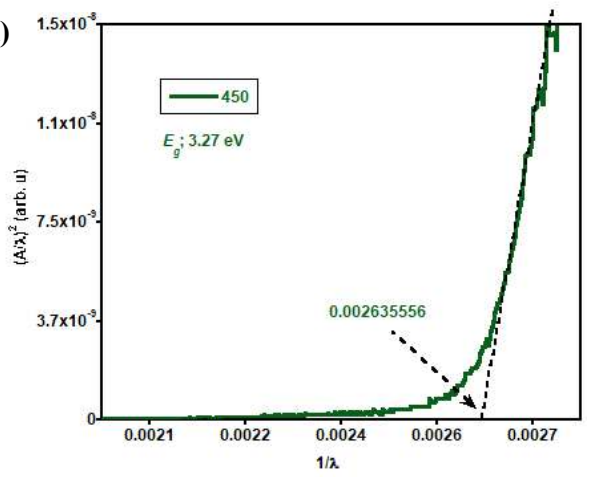

(e)

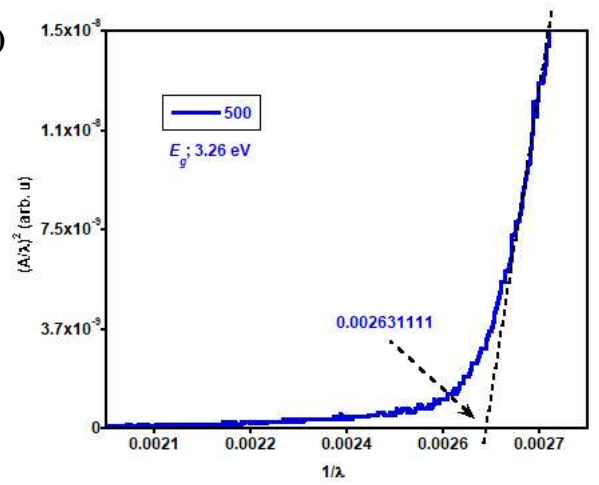

Figure 2. $E_{g}$ value measurement based on ASF plot for $\mathrm{ZnO}$ thin films annealed at; (a) 300 , (b) 350 , (c) 400 , (d) 450 , and (e) $500^{\circ} \mathrm{C}$ 


\section{CONCLUSION}

Various $\mathrm{ZnO}$ thin films have been successfully fabricated via spraying deposition method by varying post-annealing temperature. Better morphological and optical properties were achieved by annealed film. This was caused by crystallinity enhancement (lower amorphous phase) as the consequence of post-annealing treatment. Based on the characterization, $\mathrm{ZnO}$ thin film annealed at $400^{\circ} \mathrm{C}$ presented the lowest $E_{g}$ value $(3.23 \mathrm{eV})$ as compared to the non-annealed or other annealed films.

\section{ACKNOWLEDGEMENTS}

The author acknowledge the financial support from Faculty of Science and Mathematics, Universitas Negeri Semarang by DIPA research funding.

\section{REFERENCES}

1 Afre, R.A., Sharma, N., Sharon, M., \& Sharon, M. 2018. Transparent conducting oxide films for various applications: A review. Rev. Adv. Mater. Sci., Vol. 53, pp. 7989.

2 Firdaus, C.M., Rizam, M.S.B.S., Rusop, M., \& Hidayah, S.R. 2012. Characterization of $\mathrm{ZnO}$ and $\mathrm{ZnO}: \mathrm{TiO}_{2}$ thin films prepared by sol-gel spray-spin coating technique. Procedia Eng., Vol. 41, pp. 1367-1373.

3 Malek, M.F., Mamat, M.H., Soga, T., Rahman, S.A., Bakar, S.A., Ismail, A.S., Mohamed, R., Alrokayan, S.A.H., Khan, H.A., \& M. Rusop Mahmood. 2016. Thickness-controlled synthesis of vertically aligned c-axis oriented $\mathrm{ZnO}$ nanorod arrays: Effect of growth time via novel dual sonication sol-gel process. Jpn. J. Appl. Phys., Vol. 55, 01AE15.

4 Sulhadi, Usriyah, F., Wibowo, E., Astuti, B., Sugianto, Aryanto, D., \& Marwoto, P. 2019. Influence of annealing temperature on the morphology and crystal structure of Ga-doped ZnO thin films. IOP Conf. Ser. J. Phys. Conf. Ser., 1170012066.

5 Marwoto, P., Wibowo, E., Suprayogi, D., Sulhadi, Aryanto, D., \& Sugianto. 2016. Properties of $\mathrm{ZnO}: \mathrm{Ga}$ thin films deposited by dc magnetron sputtering: Influence of Ga-doped concentrations on structural and optical properties. Am. J. Appl. Sci., Vol. 13, pp. 1394.

6 Kayani, Z.N., Iqbal, M., Riaz, S., Zia, R., \& Naseem, R. 2015. Fabrication and properties of zinc oxide thin film prepared by sol-gel dip coating method. Mater. Sci., Vol. 33, pp. 515-520.

7 Gutkowski, R., Schäfer, D., Nagaiah, T.C., Heras, J.E.Y., Busser,W., Muhler, M., \& Schuhmann, W. 2014. Efficient deposition of semiconductor powders for photoelectrocatalysis by airbrush spraying. Electroanalysis., Vol. 26, pp. 1-9.

8 Cho, J., Hwang, S., Ko, D.-H., \& Chung, S. 2019. Transparent ZnO thin-film deposition by spray pyrolysis for high-performance metal-oxide field-effect transistors. Materials (Basel)., Vol. 12, pp. 3423.

9 López-Suárez, A., Acosta, D., Magaña, C., \& Hernandez, F. 2020. Optical , structural and electrical properties of $\mathrm{ZnO}$ thin films doped with Mn. J. Mater. Sci. Mater. Electron., Vol. 31, pp. 7389-7397.

10 Abdelkader, A.M., Cooper, A.J., Dryfe, R.A.W., \& Kinloch, I.A. 2015. How to get between the sheets: A review of recent works on the electrochemical exfoliation of graphene materials from bulk graphite. Nanoscale., Vol. 7, pp. 6944-6956. 
11 Suriani, A.B., Muqoyyanah, Mohamed, A., Mamat, M.H., Hashim, N., Isa, I.M., Malek, M.F., Kairi, M.I., Mohamed, A.R., \& Ahmad, M.K. 2018. Improving the photovoltaic performance of DSSCs using a combination of mixed-phase $\mathrm{TiO}_{2}$ nanostructure photoanode and agglomerated free reduced graphene oxide counter electrode assisted with hyperbranched surfactant. Opt. - Int. J. Light Electron Opt., Vol. 158, pp. 522-534.

12 Chen, C., Kelder, E.M., van der Put, P.J.J.M., \& Schoonman, J. 1996. Morphology control of thin $\mathrm{LiCoO}_{2}$ films fabricated using the electrostatic spray deposition (ESD) technique. Journal of Materials Chemistry, Vol. 6, No. 5, pp. 765-771.

13 Nadarajah, K., Chee, C.Y., \& Tan, C.Y. 2013. Influence of annealing on properties of spray deposited $\mathrm{ZnO}$ thin films. J. Nanomater. 146382.

14 Lee, J.-H., Yeo, B.-W., \& Park, B.-O. 2004. Effects of the annealing treatment on electrical and optical properties of $\mathrm{ZnO}$ transparent conduction films by ultrasonic spraying pyrolysis. Thin Solid Films., Vol. 457, pp. 333-337.

15 Yang, S., Liu, Y., Zhang, Y., \& Mo, D. 2010. Investigation of annealing-treatment on structural and optical properties of sol-gel-derived zinc oxide thin films. Bull. Mater. Sci., Vol. 33, pp. 209-214.

16 Husna, J., Aliyu, M.M., Islam, M.A., \& Chelvanathan, P. 2012. Influence of annealing temperature on the properties of $\mathrm{ZnO}$ thin films grown by sputtering. Energy Procedia., Vol. 25, pp. 55-61.

17 Ghobadi, N. 2013. Band gap determination using absorption spectrum fitting procedure. Int. Nano Lett., Vol. 3, pp. 2-5.

18 Suriani, A.B., Muqoyyanah, Mohamed, A., Mamat, M.H., Othman, M.H.D., Ahmad, M.K., Abdul Khalil, H.P.S. Marwoto, P., \& Birowosuto, M.D. 2019. Titanium dioxide/agglomerated-free reduced graphene oxide hybrid photoanode film for dyesensitized solar cells photovoltaic performance improvement. Nano-Structures \& Nano-Objects., Vol. 18, 100314.

19 Periasamy, C., Prakash, R., \& Chakrabarti, P. 2010. Effect of post annealing on structural and optical properties of $\mathrm{ZnO}$ thin films deposited by vacuum coating technique. J Mater Sci: Mater Electron., Vol. 21, pp. 309-315. 